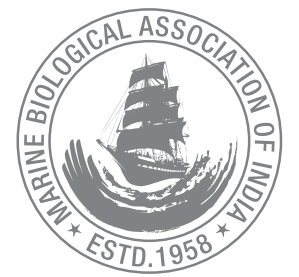

\title{
Spatial planning for integrated aquaculture development in coastal waters of Karnataka
}

\author{
A. P. Dineshbabu*, Sujitha Thomas, K. M. Rajesh, Shubhankar Dev Burman, S. Shailaja, \\ Purbali Saha and P. U. Zacharia ${ }^{1}$ \\ Research Centre of ICAR- Central Marine Fisheries Research Institute, Mangalore- 575 001, Karnataka, India. \\ IICAR- Central Marine Fisheries Research Institute, Kochi- 682 018, Kerala, India. \\ *Correspondence e-mail: dineshbabuap@yahoo.co.in
}

Received: 22 June 2019 Accepted: 31 Oct 2019 Published: 15 Nov 2019

Original Article

\begin{abstract}
Reduction in marine fish production in the last two decades has adversely affected the fishermen population along the coasts who solely depend on fishing for their livelihood. One option to tide over this situation is regional level planning to increase fish production from available water resources. Therefore, it is essential to have an integrated spatial planning of the available water resources as it has multiple uses. Marine spatial planning (MSP) and aquaculture zoning, the two major concepts implemented by international bodies, are still in its infancy in India due to, lack of information on its systematic implementation. Present paper describes the pioneering attempt of "Spatial planning" and "aquaculture zoning" in India, conducted in a progressive fishermen village, Tharapathi in Byndoor along Southeastern Arabian sea coast, following scientific methodologies. Through GIS mapping, potential aquaculture areas were identified for cage farming, bivalve farming, crab fattening/crab culture in pens in mangrove area, bottom culture of clams in sandy area, prawn farming areas, areas for seed production and nursery facility for finishes and shellfishes etc. Various advanced GIS based decision making tools available for future integrated aquaculture development plans, spatial mapping and Digital Elevation Models were included in this study. This is the first attempt to develop integrated aquaculture development through social consensus and scientific evaluation. Results of the study will be a precursor for
\end{abstract}

spatial planning and aquaculture zoning in Indian coastal waters for sustainable aquaculture.

Keywords: Spatial planning, aquaculture zoning, finfish cage culture, integrated multi-trophic aquaculture

\section{Introduction}

Since large proportion of human population along Indian coast is depending on the coastal resources especially fish, indiscriminate fishing is going on along the coast bordering Indian Ocean (Vivekanandan, 2011). In addition to the reduction in fishery the coastal fishers are also facing the threat of climate change to marine fisheries and ecosystems. Vulnerability assessment studies conducted in 68 species of finfish and shellfish along the Indian coast showed that, about $69 \%$ of the species studied are highly vulnerable to synergetic impact of climate change and anthropological interventions (Zacharia et al., 2016) along the Indian coast. Climate change lead to variations in frequency and severity of natural calamities due to high or low rainfall, heavy wind, cyclones, sea erosion, sea level rise etc., with adverse impacts on coastal population. The Food and Agriculture 
Organisation (FAO), Rome proposed practical approaches to reduce vulnerability and considerable know-how have been generated to preserve the resilience of natural ecosystems and the coastal population that inhabit them (FAO, 2009). Although fish consumption has risen, as capture fisheries has been stagnated for the last two decades, most of the consumer demand were met by farmed fishes. Developing expertise in aquaculture is suggested as an immediate alternative vocation to circumvent the low economic return from the capture fishery (De Silva, 2003). Compatibility of multiple use of coastal and marine resources have been a concern in light of rapid coastal development activities (Jarmon et al., 2004). As introduction of aquaculture practices and its development involve the use of common spaces and resources, there is a need to have consensus on sharing the common property (Fletcher and Neyrey, 2003). Therefore, aquaculture need to be designed in such a way that increased production should be achieved in harmony with the environment ensuring sustainability with absolute knowledge on carrying capacity of water bodies (Uki, 2006).

In India coastal aquaculture is still synonymous with shrimp farming, which showed spectacular developments. However long term sustainability of a single species culture has been questioned with a demand for diversification. There are lot of scope for finfish, bivalves, crab and seaweed farming (Rao, 2013) which need to be tapped with user-consensus and scientific site selection advisories. While reaching user consensus, existing activities like fishing, boat berthing, industrial development, transportation, tourism etc., need to be taken into account on a spatial platform. Application of GIS in aquaculture development was attempted in 1980s (Kapetsky and Nath, 1997), which has undergone various changes and at present GIS is often used as a decision-support tool to provide support to deal with complex issues of aquaculture and coastal planning, by providing spatially explicit approaches for resource management (Nath et al., 2000). Data in the form of mapping can support aquaculture decision-making across multiple stakeholder interests. Communication platform for subject matter specialists in GIS and fisheries was practically absent in many of the countries which was the problem in marine spatial planning with reference to fisheries development in the past (Schuurman, 2009). Integration of GIS in capture fisheries was found to be a useful tool in fisheries conservation (Dineshbabu et al., 2016). This could be extended to aquaculture planning also for sustainable use of water resources. GIS analysis and mapping can play an important role in the planning phase, especially in site selection in aquaculture for which coastal fishermen could be involved in management decisions of area sharing (Schuurman, 2009). Aquaculture zoning is a comprehensive planning process carried out by experts who can evaluate the pros and cons of different methodologies of aquaculture which lead to sustainable, integrated development of aquaculture of the region (Ross et al., 2013) and site selection for each practices and carrying capacity estimation for each aquaculture activities forms a major component of aquaculture zoning.

Preliminary attempt of use of RS and GIS in brackishwater aquaculture site selection in India was attempted by Gupta et al. (2001). With the confidence gained from application of GIS in conservation and management of marine fishery resources, marine spatial planning concept for coastal aquaculture development was attempted for the first time in Indian coast to support costal population of Karnataka to cope up with the reduction in income from capture fisheries. Pioneering attempt of aquaculture zoning was made along with marine spatial planning to maximise the production from the available water body. The concept of the exercise was to ensure integrated aquaculture development in coastal villages with sustainable practices and production with social acceptance.

\section{Material and methods}

\section{Village selected for the study}

Tharapathi Village $\left(13^{\circ} 52^{\prime} 20^{\prime \prime}\right.$ to $13^{\circ} 51^{\prime} 00^{\prime \prime} \mathrm{N}$ and $74^{\circ} 36^{\prime} 10^{\prime \prime}$ to $74^{\circ} 37^{\prime} 00^{\prime \prime} \mathrm{E}$ ) in Byndoor, Karnataka is a progressive fishing village with coastal hamlets in Karkikali and Alvekodi with Arabian Sea on one side and estuary of Suvarna river on the other side. The study area covers the Sumana river estuary, which is a part of neritic zone of Arabian Sea with important natural resources of coastal and marine system.

\section{Sampling and data analysis}

Coastal fishermen preferences and acceptance are the preliminary criteria (Ehler and Douvere, 2009) for spatial planning methodology and in the present study also social interactive methodology was followed. In advanced aquaculture zoning studies, pair-wise comparison method developed by Saaty $(1977$; 1994) with analytical hierarchy process (AHP) are being used to develop a set of relative weights for each parameter. For the present study, where the open waters, both marine and estuarine waters, were not being used for any aquaculture practices so far, the criteria of site selection of different culture practices laid down by various experts were used as baseline.

Preliminary study was conducted to understand the existing utilities of water body by enquiry. In marine zone of the study area, the priority was for capture fishing and related activities like boat berthing, fish landing and fish marketing facilities. The areas accepted for aquaculture was decided on consensus. The area that can be spared for activities other than capture fishery was marked in GIS platform (Fig. 1). For the estuarine side, as per the information navigational path was marked and 


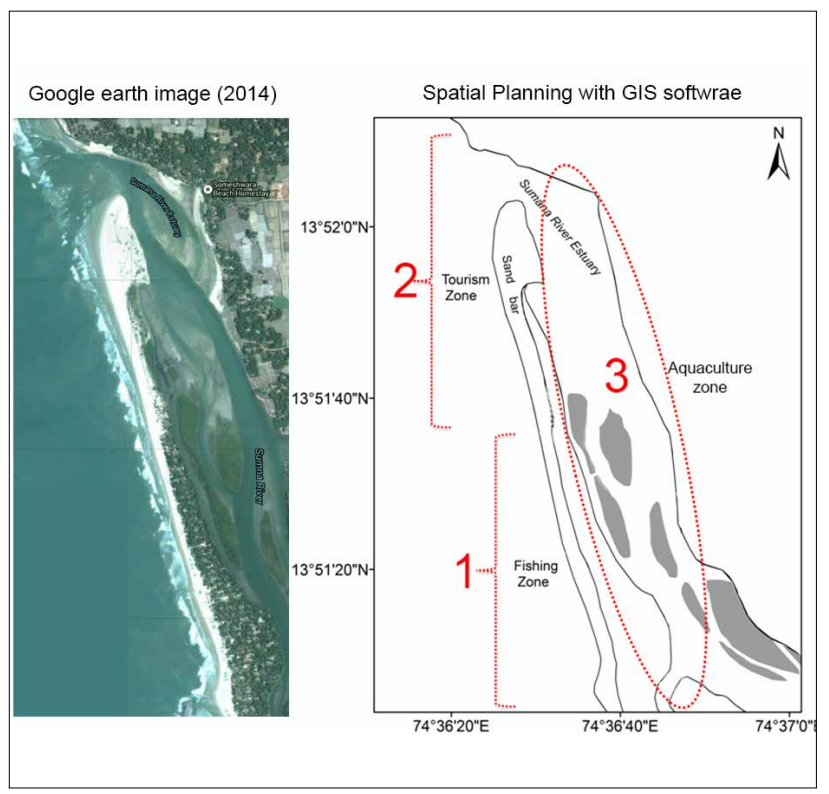

Fig. 1. Sampling sites and defining the navigation path using spatial planning concept it was delineated from the areas of aquaculture development plans (Fig. 2).

The soil and water samples were collected from five locations of the estuary during each quarter of the year (September, December, March, June) during 2014 and 2015. CTD (EXO2) was used for salinity and depth measurements. Soil sample was collected using grab for analysing the soil texture. Collection, preservation and analyses of water samples were done following standard methods (Strickland and Parsons, 1972; APHA, 2005). Temperature of the seawater was recorded in situ using a standard mercury glass thermometer and $\mathrm{pH}$ was measured using WTW multiparameter water analyser (Multi 350i) (Merck, Germany). Water samples were collected from all stations for estimating dissolved oxygen (DO following standard methods (APHA, 2005). Soil texture parameters like percentage of sand, silt and clay were analyzed using the method described by Bowman and Hutka (2002). Current speed was measured by Standard mechanical current meter method (WMO, 1980)

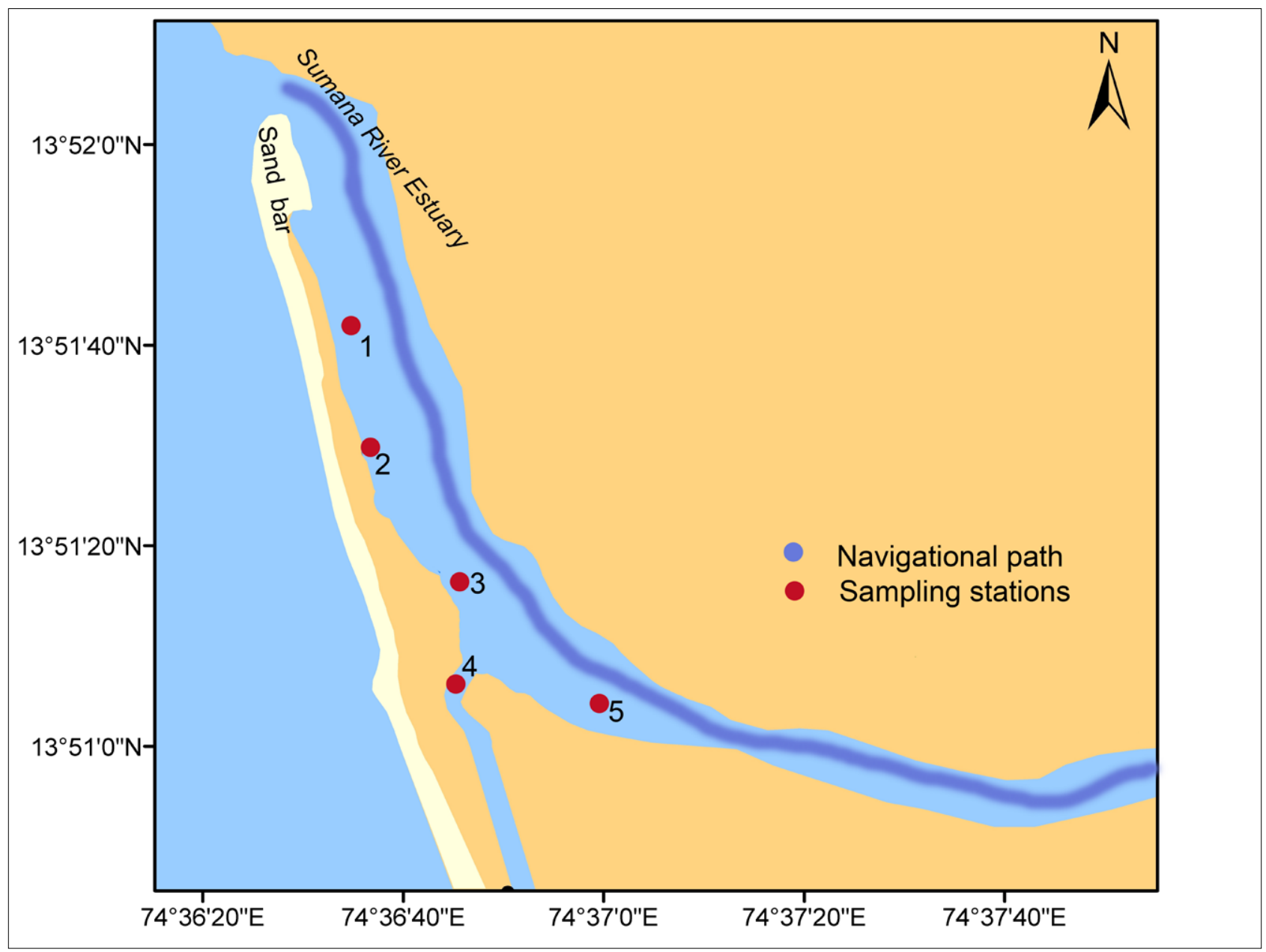

Fig. 2. Illustration of the spatial planning of Byndoor coast and Sumana-Byndoor estuarine system with special reference to coastal aquaculture development. 


\section{Hardware and Software}

The software Geomedia Professional 6.0 was used for the analysis. Map Editing, Raster Analysis, Map Layout modules of this software were used to digitalize the study area and all the features such as, road network and market facilities. Geomedia Grid software was used to interpolate and for mathematical calculation of different grid layers in the present study.

\section{Criteria used for aquaculture zoning}

Based on the baseline information, it was decided to explore the possibility of site suitability for finfish cage farming, rack culture of bivalves, pen culture of crabs and re-laying of clams. Multi-criteria decision analysis methodology (Eastman, 1996) was used for the study taking into consideration of navigational path, water current, water depth, water quality, sediment characteristics, organic load of the bottom of water body for selecting sites for coastal aquaculture. While assessing the investment capacity of the village population, it was understood that their, investment capacity is limited to low cost technologies and introduction of technologies in estuarine part was found to be more acceptable over marine side. Based on this low investment scenario, detailed aquaculture zoning was carried out in estuarine part of the village. For finfish cage farming, the criteria described by Chua (1979) and Phillips et al. (2009) was used for aquaculture zoning. For mussel culture, criteria described by Appukuttan et al. (2003), and for identifying sites for clam relaying, criteria suggested by Narasimham (1998) were used. For crab farming site selection, criteria suggested by Shelley and Lovatelli (2011) was followed, and for suggesting sites for shrimp farming and selection of hatchery and nursery sites the criteria described by Ross et al. (2013) was followed.

Methodology for "spatial planning" in which the area with respect to aquaculture and non-aquaculture activities were considered, the steps described by Ehler and Douvere (2009) and Maeden et al. (2016) was used as guideline and for "aquaculture zoning" of the area identified for aquaculture the methodologies described by Aguilar-Manjarrez et al. (2017) was followed.

For this study, open source DEM (Digital Elevation Model) data was extracted from United States. Geological Survey website and global modified ETOPO5 seafloor data was extracted from National Institute of Oceanography (NIO), India website in making demographic structure of the area. For mapping, monitoring and developing the DM model, ArcGIS domain and its underlying processes of modelling was used (Rolf GablerMieck and Rainer Duttmann, 2007).

In highly developed multiuser systems of water bodies multicriteria decision-making (pair-wise comparison) method developed by Saaty $(1994 ; 1977)$ methodologies were used to determine the highly suitable, moderately suitable and less suitable areas.

\section{Results}

\section{Social acceptance study}

Need assessment (Maeden et al., 2016) for the village was carried out in the selected area to understand the acceptance of aquaculture development in water bodies around the selected village. Alvekodi, one of the northern hamlet at the mouth of Suvarna River is a hamlet with active fishing and fish landing areas, long and clean beach extending to river mouth. Greenery is mainly formed by coconut plantations and rich assemblage of mangroves. Google Earth map of 2014 was used as a preliminary tool for interacting with the coastal population. Google map of the area was downloaded and the activities in the coastal areas were digitised using GIS software with sea and land truth information collection (Fig.1)

Major activities inventoried in marine part of the village were: Areas of fishing by traditional and mechanised boat with extensive channels for their regular free movement, berthing. Areas being used for tourism or can be developed for tourism with water sports.

\section{Areas with aquaculture potential for opensea farming}

Most coastal fishermen in the village depend on coastal and estuarine fishing. Marine zone is traditionally used for fishing, fish landing and boat berthing activities, and the stakeholders felt that there was no space left for other developments. This zone was specified for fishing and allied activities alone (No.1 in Fig.1). Areas not used for fishing and allied activities were considered for future tourism activities, aqua-tourism with marine cages, bivalve farming and sea weed farming (No.2 in Fig. 1). Byndoor river and its catchment was mainly used for navigation and estuarine fishery which was only income generation activity from the estuary, which was also partially abandoned due to non-feasibility as a fulltime vocation. These areas were suggested for further development of aquaculture development and in the preliminary zoning these areas were marked as aquaculture zone (No. 3 in Fig. 1). While carrying out aquaculture zoning, the areas presently used for shrimp farming was also included as potential aquaculture zones. Indications of the areas of high organic load was also indicated in the map, to make aware the future entrepreneurs. Similarly looking at the future development in coastal aquaculture, areas suitable for hatchery and nursery construction of seed production and seed rearing of finfishes and shellfishes were also marked. 


\section{Aquaculture zoning}

Aquaculture zonation of Sumana-Byndoor Estuary was carried out based on physico-chemical qualities of water bodies. Among the five sites studied, site 5 had maximum depth of 2-3m (Table 1). Water quality characteristics such as temperature, salinity and DO were found to be almost similar at all sites. Surface current was highest at Site 1 and lowest at site 3. Through GIS based calculation area potentially available for each practices were also identified (Table 2 and Fig. 3).

Table 1. Hydrographical and environmental characteristic of sites studied

\begin{tabular}{llllll}
\hline Site and criteria & Site 1 & Site 2 & Site 3 & Site 4 & Site 5 \\
\hline Depth(m) & $0.5-1.5$ & $1-1.5$ & $2.0-3.0$ & $1.0-2.0$ & $2.0-4.0$ \\
\hline Temperature (OC) & $28.2-30.3$ & $28.2-30.1$ & $27.9-30.1$ & $27.4-29.3$ & $26.4-29.3$ \\
\hline Salinity(ppt) & $25.4-34.9$ & $24.8-34.6$ & $20.5-34.2$ & $18.5-33.8$ & $16.5-33.2$ \\
\hline $\mathrm{pH}$ & $7.4-8.3$ & $7.0-7.9$ & $7.2-8.5$ & $6.4-8.0$ & $7.5-8.3$ \\
\hline Dissolved oxygen(mg/l) & $6.4-7.5$ & $4.6-6.2$ & $5.7-6.1$ & $2.6-4.7$ & $5.4-6.5$ \\
\hline $\begin{array}{l}\text { Surface Current speed } \\
\text { (cm/sec) }\end{array}$ & $32-42$ & $20-24$ & 24-35 & 16-24 & 24-32 \\
\hline Bottom characteristics & Sandy & Silty & Rocky & Silty & Sandy/Silty \\
\hline & & \multicolumn{5}{l}{}
\end{tabular}

Table 2. Potential suitable space (water body and land) available for different coastal aquaculture practices estimated through aquaculture zoning.

\begin{tabular}{ll}
\hline Total Study Area & $3 \mathrm{sq} . \mathrm{km}$ \\
\hline Projected Aquaculture Zone & $0.12 \mathrm{sq} . \mathrm{km}(120000 \mathrm{sq} . \mathrm{m})$ \\
\hline Type of Aquaculture Activities & Estimated Area \\
\hline 3(i). Prawn farms & 15000 sq. $\mathrm{m}$ \\
\hline 3(ii). Small scale cage culture /Mussel racks & 35000 sq. m \\
\hline 3(iii). Hatchery complex potential site & 7500 sq. m \\
\hline 3(iv). Crab culture potential area & 47500 sq. m \\
\hline 3(v). Clam fishery and farming & 15000 sq. m \\
\hline 3(vi) Mangroves & $1 . \mathrm{sq} . \mathrm{km}$ \\
\hline
\end{tabular}

\section{D demographic structure of the study for site suitability}

To demonstrate the availability of the technological support and also to demonstrate the utility of advanced GIS tools in solving aquaculture problems arising in future, $3 \mathrm{D}$ demographic structure of the study for site suitability was also introduced or the first time in Indian aquaculture scenario. GIS technology was used here to provide the information for micro and macrolevel spatial planning of natural resources of coastal areas in India on a sustainable basis. Raster surface Extraction were applied for geographical referencing, projecting the area and generating contour lines. This technique helped in identifying the suitable area for ecological coastal activities like mangroves conservation, bivalve fishery, prawn farms, crab culture potential area, small scale cage culture site, and areas of high organic load. As a result of the process an exclusive 3D demographic structure of the study area was modelled, which contains valuable information

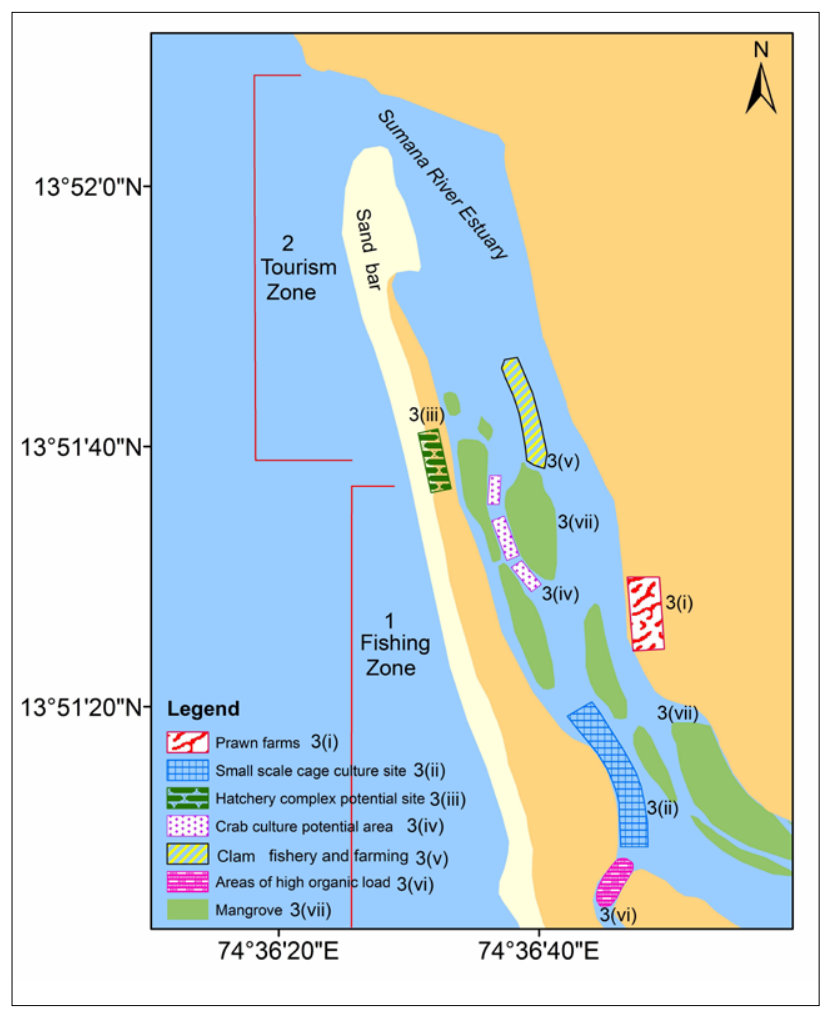

Fig. 3. Pictorial representation of aquaculture zones of Byndoor Sumana Estuary

of the area, future possibilities and scopes for using natural resources from coastal area. This spatial information helped in depicting the various uses of coastal ecosystem and human interfaces and also to project the possible interventions from that area in future.

\section{Discussion}

For establishing a successful and sustainable aquaculture industry, site selection is considered as a key factor. Site section for aquaculture development focussed mainly on physicochemical parameters of water and not much care was given to social acceptance of the technology. For decision making in aquaculture site section, GIS technology offers unique capabilities with providing spatial component to involve the stake holders in decision making process. It helps in analysing a variety of spatial data for decision-making. The area which was not suited for farming in preliminary survey was not included in the study. To introduce the decision making tools available for entrepreneurs and policy makers in India in GIS based modelling, spatial mapping (Aguilar-Manjarrez et al., 2017) and DEM (Digital Elevation Model) (Rolf Gabler-Mieck and Rainer Duttmann, 2007) are included in this study. In future aquaculture development in India, policy makers can make use of such applications for the integrated sustainable development. The sites studied are classified as follows 
Site 1: Site 1 is very near to bar mouth and the bottom was found to be sandy throughout the study period, the depth was 0.5 to $1 \mathrm{~m}$ in lowest low tide and highest high tide water quality and current flow as very suitable for aquaculture practices. The depth range was less than $2 \mathrm{~m}$, which disqualify the site for cage farming practices. The site satisfies the site section criteria suggested by Narasimham (1998), and therefore it was suggested for clam fishing and clam relaying.

Site 2: Site 2 is tidal creek within a mangrove belt (Fig. 3) which is presently used as fishing ground for mud crabs. As per GIS based area estimation, mangrove areas in the part of the estuary studied was about $1 \mathrm{~km}^{2}$, of which $47,500 \mathrm{~m}^{2}$ can be used for crab farming (Table.2). Here the bottom remained silty through put the period of study, the flow rate was comparatively low, all other physico-chemical parameters fall within the site selection criteria for mud crab farming described by Shelley and Lovatelli (2011). The low depth disqualify the site for finfish cage farming and the silty bottom make it unsuitable for clam relaying. Since these areas were found to be a natural habitat for the crabs, crab fattening and culture of mud crabs can be taken up in this site using pens. The integration of crab aquaculture within natural mangroves proved to be highly feasible venture in many parts of the world (Aldon, 1997) providing commercial and environmental benefits for the coastal population. In the present scenario the economic utilisation of mangrove areas will in turn help in increasing livelihood avenues for the coastal population as well as it leads to conservation of the mangroves by understanding its economic value (Bagarinao, 1998). Since seed production techniques are perfected for mud crabs in India (Marichamy and Rajapackiam, 2001) bringing such nonexploited areas for crab aquaculture will help in improving the local and National economy.

Site 3: Site 3 has very good flow rate and depth suitable for installation of estuarine cages. The physico chemical criteria (Table.1) is suitable as suggested by Chua (1979) and Phillips et al. (2009) for finfish cage culture and for mussel culture by Appukuttan et al. (2003). According to Chua (1979), current speed above $20 \mathrm{~cm} / \mathrm{sec}$ is found to be efficient for flushing out waste materials and providing sufficient oxygen in estuaries, the condition at site 3 ensure healthy growth of fin fishes. The proven technology for successful finfish farming is already adopted by many farmers in nearby villages (Dineshbabu, 2012; Dineshbabu et al., 2012). Following similar technology, the coastal fishermen in this village also can practice finfish cage farming in site 3 . Similarly bivalve culture is also a proven technology in Karnataka (Sasikumar and Krishnakumar, 2012), suspended farming of mussel as well as oysters can be advocated for higher production from this site. Cranford et al. (2013) illustrated that combination of finfish cages with bivalve farming lead to better production from both culture practices and such combination of integrated multi trophic aquaculture (IMTA) practices also can be introduced in this site to increase the production from the limited water body. Total area estimated for farming was about $35,000 \mathrm{~m}^{2}$ (Table. 2).

Site 4: This site has slow flow rate, and with lots of organic load accumulated in the silt dominated bottom (Table.1). Silty bottom, slow flow rate and low DO content in some seasons (2.6mg/l during December) disqualify this site for the perennial farming practices. This site should not be considered as a priority area for any of the aquaculture practices.

Site 5: This was having a depth of $2 \mathrm{~m}$ and above throughout the year and have a good flow rate of more than $25 \mathrm{~cm} /$ second throughout the study period and it shares almost all the features of site 3 except the bottom features. Similar to site 3 finfish cage culture, suspended culture of bivalves and integrated multi-trophic farming of bivalves and finfishes also can be taken up in these areas.

Apart from these sites, shrimp farms, which was abandoned after trial farming are also proposed as future aquaculture production centres through shrimp farming area with provision of inlet and outlet in the navigational channel away from fish cage farming activities.

Near the sea shore, $7500 \mathrm{~m}^{2}$ is earmarked for future development of multiple hatchery nursery system which justifies the conditions or marine fish cum shellfish hatcheries described by Ross et al. (2013). These provide direct access to seawater and have accessibility through road, sea and estuary (Fig. 3).

Maeden et al. (2016) while preparing a document on "Marine spatial planning for enhanced fisheries and aquaculture sustainability" have emphasized the importance of spatial planning. Marine spatial planning should ultimately lead to sharing of information between the resource users which should help to build trust and cooperation among the many stakeholders involved in the marine spatial planning process. Spatial planning will help allocating water bodies and coastal land mass for aquaculture fishery and non-fishery activities, but for further development of aquaculture, zoning of the spaces allocated for different culture practices are very much important (Aguilar-Manjarrez et al., 2017). Aquaculture zoning is highly regional and local specific for which sound knowledge of physical, chemical and biological requirement of different species used for different aquaculture practices are very much important.

It is widely accepted fact that spatial analysis and spatial applications in aquaculture that relate to ecosystems is the most realistic solution in impact assessment studies for projecting 
the probable impacts of cage installation and cage culture. GIS projections are capable to resolve conflicts for space and resources between stakeholders and also to help to understand the social acceptability and the economic implications of mariculture. GIS based spatial planning provides the projection scenarios of various physical and biological parameters and will help the stakeholders to come out with suggestions on species suitability for cages, carrying capacity of the water body, stocking density of the cages and the best feeding strategies and feeding schedules incorporating all chemical, biological and physical features.

Spatial planning and modelling with GIS especially in marine systems in India is still in the nascent stage., the paper points out that the technology, and the technologist to use the software as well as the research personnel who can analyse the data coming out of technological projections are handy in India and an earnest effort is required to integrate these groups, to effectively use GIS based applications in encouraging coastal aquaculture and mariculture development in the country Estimation of carrying capacity of each type of culture operation is an indispensable requirement for proposing sustainable aquaculture through regulated development. The user friendly ArcGIS software has extended its application in the marine resource management and acts as a support system to make decisions and policies in coastal natural resource management to be incorporated for the estimation. For this, along with introduction of technologies, the evaluation of the environmental and ecological changes should be evaluated to apportion the carrying capacity of each aquaculture operation for integrated sustainable growth.

\section{Acknowledgements}

The authors are thankful to Dr. A. Gopalakrishnan, Director, ICAR-Central Marine Fisheries Research Institute (CMFRI), Kochi, and Dr. Prathibha Rohit, Scientist-in-Charge, CMFRI, Mangalore, for the facilities provided for this work. The authors are thankful to the Indian Council of Agriculture-National Innovations for Climate Resilient Agriculture (NICRA) project for funding this study. The co-operation and help provided by the coastal population of Tharapathi Village, Karnataka, India are also acknowledged with gratitude.

\section{References}

Aguilar-Manjarrez, J., D. Soto and R. Brummett. 2017. Aquaculture zoning, site selection and area management under the ecosystem approach to aquaculture. A handbook. Report ACS18071. Rome, FAO, and World Bank Group, Washington, DC. $62 \mathrm{pp}$.

Aldon, E. T. 1997. Mud crab culture in mangrove areas, SEAFDEC Asian Aquacult., p. 21-22.

APHA, 2005. Standard Methods for the Examination of Water and Wastewater. 21st Edition, American Public Health Association/American Water Works Association/ Water Environment Federation, Washington DC: $1 \mathrm{v}$. [various pagings]

Appukuttan, K. K., P. K. Asokan, K. S. Mohamed, S. Subramanian and K. George
Joseph. 2003., Eds: S. Subramanian P. K. Asokan. Manual of Mussel farming. Technical Bulletin No.3, ICAR Research Complex for Goa: 28pp.

Avelino T. Trino and E. M. Rodriguez. 2002, Pen culture of mud crab Scylla serrata in tidal flats reforested with mangrove trees. Aquaculture, 211(1):125-134.

Bagarinao, T., 1998. Milkfish ponds from mangroves. SEAFDEC Asian Aquacult. XX (2), $5-6$.

Bowman G. M. and J. Hutka. 2002. Particle Size Analysis. In Soil Physical Measurement and Interpretation for Land Evaluation: (Eds N McKenzie, K Coughlan, H Cresswell). CSIRO Publishing: Victoria: p. 224-23.

Chua, T. E. 1979. Site selection, structural design, construction, management and production of floating cage culture system in Malaysia. In Proceedings of the International Workshop on Pen Cage Culture of Fish, 11-22 February 1979 Tigbauan, Iloilo, Philippines, p. 65-80.

Cranford, P. J., G. K. Reid and S. M. C. Robinson. 2013. Open water integrated multitrophic aquaculture: constraints on the effectiveness of mussels as an organic extractive component. Aquacult. Env. Interac., 4: 163-173.

De Silva, S. S. 2003. Culture-based fisheries: an underutilized opportunity in aquaculture. Aquaculture, 221: 221-243.

Dineshbabu, A. P. 2012. Cage farming of finfishes in estuaries. In: Handbook on Opensea cage Culture. Philipose, K. K. and Loka, Jayasree and Sharma, S. R. Krupesha and Damodaran, Divu, (eds.) Central Marine Fisheries Research Institute, Karwar, p. 137-144.

Dineshbabu, A. P., Sujitha Thomas, P. S. Swathilekshmi and Geetha Sasikumar. 2012. Adoption of sustainable capture based aquaculture practices by traditional fishermen of Karnataka. Indian J. Fish., 59(1): 49-52

Dineshbabu, A. P., Sujitha Thomas and A. C. Dinesh. 2016. Handbook on Application of GIS as a Decision Support Tool in Marine Fisheries, CMFRI Spl Publ. No. 121. ICAR-Central Marine Fisheries Research Institute, Kochi.

Eastman, J. R. 1996. Uncertainty and decision risk in multi-criteria evaluation: implications for GIS software design. Proceedings, International Institute for Software Technology Expert Group Workshop on Software Technology for Agenda 21: Decision Support Systems Section 8.

Ehler, Charles and Fanny Douvere. 2009. Marine Spatial Planning: a step-by-step approach toward ecosystem-based management. Intergovernmental Oceanographic Commission and Man and the Biosphere Programme. IOC Manual and Guides No. 53, ICAM Dossier No. 6. Paris: UNESCO. 2009 (English).

FAO. 2009. Environmental impact assessment and monitoring in aquaculture. FAO Fisheries and Aquaculture Technical Paper No. 527. Rome, FAO. 649 pp. (available at http://www.fao.org/docrep/012/i0970e/i0970e00.htm)

Fletcher, K.M. and E. Neyrey. 2003. Marine Aquaculture Zoning: A Sustainable Approach in the Growth of Offshore Aquaculture; The World Aquaculture Society: Baton Rouge, LA, USA, 15 pp.

Gupta. M. C., V. P. Krishnarajan and Shailesh Nayak. 2001. Brackishwater Aquaculture Site Selection in Coastal Track of Cannanore (Kerala) Using Remote Sensing and GIS Techniques, J. Indian Soc. Remote., 29( I\&2): 80-83.

Jarmon, C., D. Au Bellatti and S. Mowrey. 2004. Legal Issues Surrounding the Development of Sustainable Forms of Aquaculture in Hawai i; Publication \# 2004-3; University of Hawaii at Manoa, William S. Richardson School of Law: Honolulu, HI, USA, 2004.

Kapetsky, J. M. and S. S. Nath. 1997. A strategic assessment of the potential for freshwater fish farming in Latin America. COPESCAL technical paper128, FAO, Rome, Italy

Marichamy. R and S. Rajapackiam. 2001. The Aquaculture of Scylla Species in India. Asian Fish. Sci., 14: 231-238.

Meaden, G. J., J. Aguilar-Manjarrez, R. A. Corner, A. M. O'Hagan and F. Cardia. 2016. Marine spatial planning for enhanced fisheries and aquaculture sustainability - its application in the Near East. FAO Fisheries and Aquaculture. Technical Paper No. 604. Rome, FAO.

Narasimham, K. A. 1998. Clam culture. In: Proceedings of the Workshop National Aquaculture Week. The Aquaculture Foundation of India, Chennai, p. 134-140.

Nath, S.S., J. P. Bolte, L. G. Ross, J. Aguilar-Manjarrez. 2000. Applications of geographical information systems (GIS) for spatial decision support in aquaculture. Aqua. Eng., 23: 233-278

Phillips, M. J., F. Enyuan, F. Gavine, T. K. Hooi, M. N. Kutty, N. A. Lopez, R. Mungkung, T. T. Ngan, P. G. White, K. Yamamoto and H. Yokoyama. 2009. Review of environmental impact assessment and monitoring in aquaculture in Asia Pacific. In FAO. Environmental impact assessment and monitoring in aquaculture. FAO Fisheries and Aquaculture Technical Paper. No. 527. Rome, FAO. p. 153-283.

Rao, G S. 2013. Way forward for enhancing Indian Marine Fish Production-With Developmental Measures Suggested for Adoption. Fishing Chimes, 33 (1 \& 2): 57-63.

Rolf Gabler-Mieck and Rainer Duttmann. 2007. Application of Geo-visualisation Techniques in Coastalzone Management. Retrieved September 10, 2011, from: http://people.plan.aau.dk/ enc/AGILE2007/PDF/129_PDF.

Ross, L. G., T. C. Telfer, L. Falconer, D. Soto and J. Aguilar-Manjarrez. 2013. Site 
selection and carrying capacities for inland and coastal aquaculture. FAO/Institute of Aquaculture, University of Stirling, Expert Workshop, 6-8 December 2010. Stirling, the United Kingdom of Great Britain and Northern Ireland. FAO Fisheries and Aquaculture Proceedings No. 21. Rome, FAO. 46 pp.

Saaty, T. L. 1977. A scaling method for priorities in hierarchical structures. J. Math. Psychol., 15: 234-281.

Saaty, T. L. 1994. How to make a decision: the analytic hierarchy process. Interfaces, 24(6): 19-43.

Sasikumar, Geetha and P. K. Krishnakumar. 2011. Aquaculture planning for suspended bivalve farming systems: The integration of physiological response of green mussel with environmental variability in site selection. Ecol. Indic., 11: 734-740.

Schuurman, N. 2009. Critical GI Science in Canada in the new millennium. Can. Geogr., 53: 139-144.

Shelley, C. and A. Lovatelli. 2011. Mud crab aquaculture - A practical manual. FAO Fisheries and Aquaculture Technical Paper. No. 567. Rome, FAO. 2011. $78 \mathrm{pp}$.

Strickland, J. D. H. and T. R. Parsons. 1972. A Practical Handbook of Seawater Analysis. 2nd Edition, Fisheries Research Board of Canada Bulletin, No. 167, Fisheries Research Board of Canada, $310 \mathrm{pp}$.

Uki, N. 2006. Stock enhancement of the Japanese scallop Patinopecten yessoensis in
Hokkaido. Fish. Res., 80: 62-66.

Vivekanandan, E. 2011. Climate Change and Indian Marine Fisheries. CMFRI Special Publication, 105: 97

WMO, 1980. Manual on Stream Gauging. Fieldwork. Vol II, Computation of Discharge. Operational Hydrology Report No. 13; WMO-No. 519, World Meteorological Organization, Geneva: $254 \mathrm{pp}$.

Zacharia, P. U., A. P. Dineshbabu, Sujitha Thomas, Shoba Joe Kizhakudan, E. Vivekanandan, S Lakshmi Pillai, M. Sivadas, Shubhadeep Ghosh, U. Ganga, K. M. Rajesh, J. Rekha Nair, T. M. Najmudeen, Mohammed Koya, Anulekshmi Chellappan, Gyanranjan Dash, Indira Divipala, K. V. Akhilesh, M. Muktha, and Swatipriyanka Sen Dash. 2016. Relative vulnerability assessment of Indian marine fishes to climate change using impact and adaptation attributes. CMFR Special Publication 125 ICAR-Central Marine Fisheries Research Institute, Kochi 